\title{
International PV QA Task Force's proposed comparative rating system for PV modules
}

John Wohlgemuth, Sarah Kurtz

John Wohlgemuth, Sarah Kurtz, "International PV QA Task Force's proposed comparative rating system for PV modules," Proc. SPIE 9179, Reliability of Photovoltaic Cells, Modules, Components, and Systems VII, 917902 (6 October 2014); doi: 10.1117/12.2067927

SPIE Event: SPIE Solar Energy + Technology, 2014, San Diego, California, United States 


\title{
International PV QA Task Force's Proposed Comparative Rating System for PV Modules
}

\author{
John Wohlgemuth and Sarah Kurtz \\ National Renewable Energy Laboratory, Golden, CO, USA 80401
}

\begin{abstract}
The International PV Quality Assurance Task Force is developing a rating system that provides comparative information about the relative durability of PV modules. Development of accelerated stress tests that can provide such comparative information is seen as a major step toward being able to predict PV module service life. This paper will provide details of the ongoing effort to determine the format of such an overall module rating system. The latest proposal is based on using three distinct climate zones as defined in IEC 60721-2-1 for two different mounting systems. Specific stresses beyond those used in the qualification tests are being developed for each of the selected climate zones.
\end{abstract}

Keywords: reliability and durability of PV modules, accelerated stress testing, service life predictions

\section{INTRODUCTION}

The commercial success of PV is based on the long term reliability and safety of the deployed PV modules. While the PV modules are often considered the most reliable part of the PV system, the potential cost of failure for modules is higher than for any of the other components of the system. It is extremely expensive to replace all or most of the modules in a PV system. So as PV systems become larger and larger, it is important that we have a test protocol that can help to determine which modules will survive best in a particular environment.

The PV industry has a long history of providing reliable products. Most commercial PV modules come with at least a twenty-five year warranty and have been qualified to either IEC 61215 [1] or IEC 61646 [2]. As early as 1993, Whipple [3] reported that after field exposure, module types that had not been certified to the qualification tests had failure rates of $45 \%$ in the first 10 years, while module types that were qualified had 10 year failure rates of less than $0.1 \%$. These qualification tests do an excellent job of identifying design, materials and process flaws that could lead to premature field failures. However, the qualification tests are not designed to test for module wear out. While there are numerous reports of modules that have survived in the field for more than 25 years, there are also reports of qualified module types that have failed in the field before reaching the 25 year lifetime. The warranty will be of little use in this case if the module manufacturer has gone out of business.

To address this, the International PV Module Quality Assurance Forum was held in 2011. The Forum created the International PV Module QA Task Force (PVQAT). The goals of PVQAT are to:

1) Develop a QA rating system that provides comparative information about the relative durability of PV modules; and

2) Create a guideline for factory inspections of the QA system used during PV module manufacturing.

PVQAT is an effort to develop a PV module rating system that meets needs of all countries and customers, that is a single test protocol. It is working to define concepts for creation of standards that allow stakeholders to quickly assess a module's ability to withstand regional stresses. Participation in PVQAT is open to all who want to contribute to the effort. The program relies on research done by volunteers around the world. Its effort is to guide world-wide research to answer important questions related to testing that predicts outdoor performance of PV modules. Today PVQAT has 11 task groups working on various aspects of PV reliability (See Table 1)

This paper will describe the PVQAT efforts underway to develop a Comparative Testing Protocol to better evaluate the ability of PV modules to survive in the field.

Reliability of Photovoltaic Cells, Modules, Components, and Systems VII, edited by Neelkanth G. Dhere, John H. Wohlgemuth, Rebecca Jones-Albertus, Proc. of SPIE Vol. 9179, 917902 - (c) 2014 SPIE CCC code: $0277-786 \mathrm{X} / 14 / \$ 18 \cdot$ doi: $10.1117 / 12.2067927$ 
Table 1: PVQAT Task Groups

\begin{tabular}{|c|l|}
\hline Group \# & \multicolumn{1}{|c|}{ Task Group Name } \\
\hline 1 & PV QA Guidelines for Module Manufacturing \\
\hline 2 & Testing for thermal and mechanical fatigue \\
\hline 3 & Testing for humidity, temperature and voltage \\
\hline 4 & Testing for diodes, shading and reverse bias \\
\hline 5 & Testing for UV, temperature and humidity \\
\hline 6 & Communications of rating information \\
\hline 7 & Testing for snow and wind load \\
\hline 8 & Testing for thin film modules \\
\hline 9 & Testing for CPV \\
\hline 10 & Testing for Connectors \\
\hline 11 & QA for PV Systems \\
\hline
\end{tabular}

\section{ESTABLISHING THE TEST MATRIX}

One of the first steps in developing a draft standard for comparative testing was to understand what the PV industry wanted in terms of rating beyond qualification. Companies prefer descriptive ratings rather than grades. This means it would be acceptable to rate modules for special climates (desert or tropical) or for special conditions (extra wind load, high snow load, or larger hail stones), but companies would prefer not to rate modules A, B or C based on passing different levels of a test.

This led to a decision to use different climate zones as the PV modules may have to work anywhere in the world. A logical choice was then to use IEC 60721-2-1 [4], which breaks the world into a fairly large number of different climate zones. To use all or even many of these would likely result in a very confusing system. However, 60721-2-1 does provide some classifications that combine many climate zones into larger categories. One such category is called "moderate" and includes much of the world outside places with extreme climates. Therefore we selected "moderate" as one of our climate categories and only added 2 additional climate zones - warm damp, equable (tropical) and extremely warm and dry (deserts).

A second variable that significantly changes the operating conditions of a PV module is the type of mounting. While a range of mounting systems are utilized for PV modules, only two categories were selected, open rack mount with no insulation on the module back and roof mount where the module backs are fully insulated by the roof. These are the two extremes in terms of operating temperature as open rack provides maximum cooling while roof mount restricts all cooling from the back side of the module. Table 2 shows the layout of the proposed rating system.

The efforts underway in PVQAT have been focused on determining what failure modes are occurring in the field in module types that have been qualified to IEC 61215. This effort has identified three major field failure modes:

- $\quad$ Broken interconnect ribbons, degraded solder bonds and cracked cells.

- Delamination of encapsulants (that may result in corrosion of metallization in the module).

- Encapsulant discoloration.

The next section will discuss the selection of the accelerated stress tests proposed for each of these observed field failure modes. 
Table 2: Proposed Comparative Test Matrix

\begin{tabular}{|l|c|c|}
\hline $\begin{array}{l}\text { IEC 60721-2-1 Climate } \\
\text { Designation }\end{array}$ & \multicolumn{2}{|c|}{ Mounting classes } \\
\hline & Rack mount & Close-roof mount \\
\hline Moderate (Temperate) & $\checkmark$ & $\checkmark$ \\
\hline Warm Damp, Equable (Tropical) & $\checkmark$ & $\checkmark$ \\
\hline Extremely Warm Dry (Desert) & $\checkmark$ & $\checkmark$ \\
\hline
\end{tabular}

\section{SELECTION OF TEST LEGS}

\subsection{Test leg for broken interconnects and degraded solder joints}

Failures of solder bonds and ribbons in the module laminate have dominated the field failure Pareto charts in a number of studies [5]. The Module Qualification Test IEC 61215 already contains 200 thermal cycles (from $-40^{\circ} \mathrm{C}$ to $+85^{\circ} \mathrm{C}$ with maximum power current flow when the modules are above room temperature) to detect such failures. Field data indicate that module types that survive this 200 thermal cycle test have still suffered broken interconnects and degraded solder bonds in the field over times that are significantly less than the warranty period. [6] Bad solder bonds (See Figure 1) can be the result of either manufacturing defects or design related for example using too few solder bonds per tabbing ribbon or designing the process to make bonds that are too small. Failure of interconnect ribbons (See Figures 2) are almost always related to poor design; for example using a ribbon material that is too stiff or too thick or not leaving enough free ribbon length between cells.

Figure 1. Example of overheated solder bond.

Figure 2: Picture of broken interconnect ribbon in module
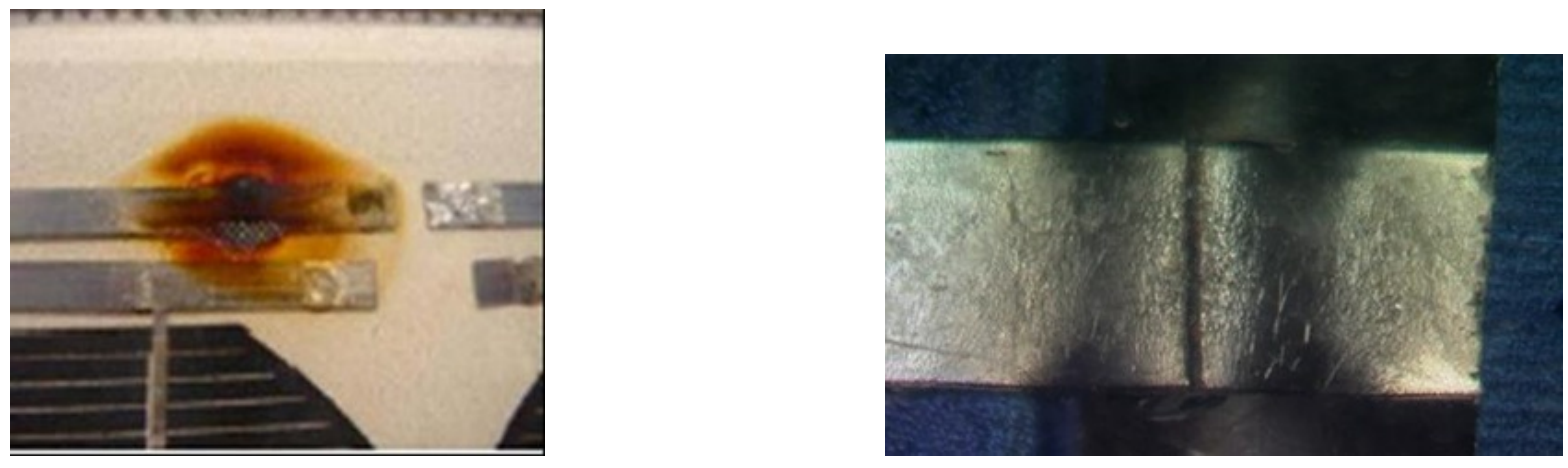

Therefore this 200 thermal cycle test does not provide enough stress to validate modules for a 25 -year warranty. The main questions then are how many thermal cycles should be used for the test and should the cycles be the same for the different climate zones and mounting configurations? Recent work indicates that modules susceptible to such failures begin to show significant power loss between 400 and 600 cycles [7] [8] (See Figure 3 for the thermal cycle data from Ref 7.) A preliminary level of 500 thermal cycles was proposed for all climates and mountings because this level has been utilized by a number of module manufacturers in the past [9].

We expect that there will be a significant amount of discussion about the selection of 500 thermal cycles as this test will take 65 days or more to meet the present test specification. It may be possible that the failures seen in the field are 
largely the result of poor quality control and that tighter controls on quality would be as effective as increasing the design requirement. There is also the issue of whether the temperature range shouldn't be modified for roof mount in the extremely warm climate zone where modules are likely to reach temperatures higher than $85^{\circ} \mathrm{C}$ almost every day during the summer. Should modules designed for use in this category be cycled from $-25^{\circ} \mathrm{C}$ to $+100^{\circ} \mathrm{C}$ ? Are the thermal cycles in this climate zone more or less stressful than those in the temperate climate?

Figure 3: Power loss as a function of thermal cycles from reference 7.

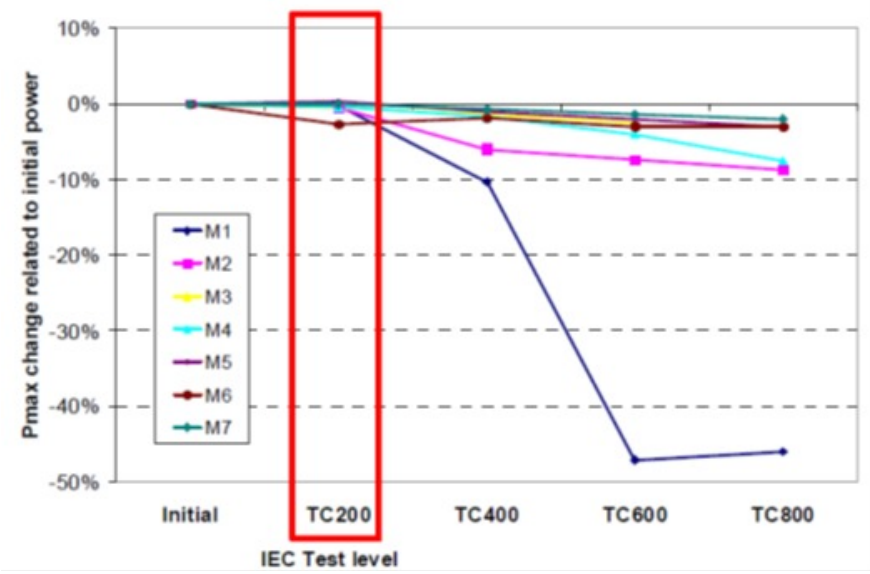

\subsection{Test leg for encapsulant delamination}

Corrosion of the metallization within a PV module is another failure mode often observed in the field (See Figures 4 and 5). In most cases such a degree of corrosion is observed in conjunction with delamination of the encapsulant from either the superstrate or the cell surface. As the figures show, such corrosion happens in both humid and dry climates. In the module in Figure 4 the delamination appears to be between the encapsulant and the cell surface probably because the formulation of EVA did not contain a primer. The glass was manually primed during the module manufacturing process. The module in Figure 5 has a glass/glass construction with a non-EVA encapsulant that does not adhere well to glass. Over time thermal stresses caused delamination between the encapsulant and the glass allowing liquid water to condense inside the package during the cool night time. We need a test sequence that will duplicate each of these failure modes.

Figure 4: Corrosion of cell metallization from Florida

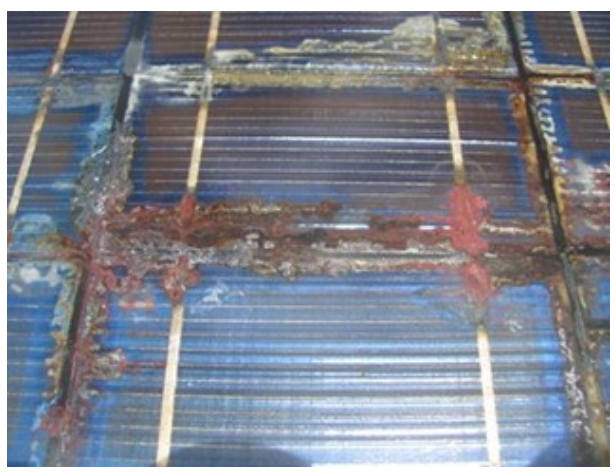

Figure 5: Corrosion of cell metallization from Arizona

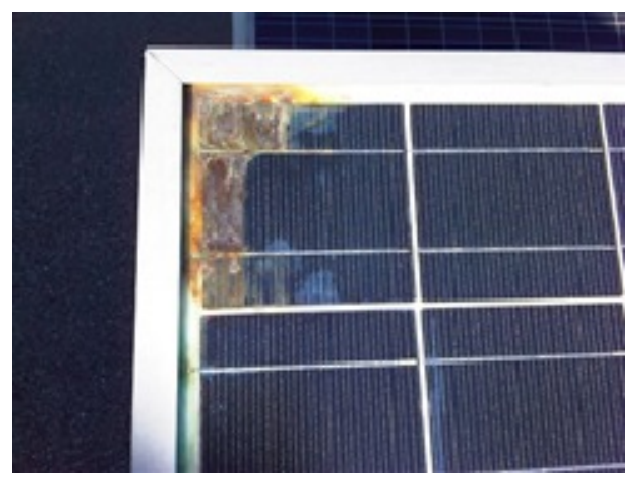

We need to find an accelerated stress test or sequence of tests that can duplicate the delamination and corrosion processes observed in fielded modules. IEC 61215 contains an extended damp heat test $\left(1000\right.$ hours at $85^{\circ} \mathrm{C} / 85 \%$ relative humidity). While this test does cause failures, neither the thousand hour test from IEC 61215 nor extension of this test to longer times results in the type of delamination observed in fielded modules. Delaminations in the damp heat test tend to occur at the edges of the module not over the cells. Extending the damp heat test for long time periods causes 
power degradation in many types of PV modules. However, that type of degradation has not been reported in field observations [10]. Damp heat testing alone is not the answer.

IEC 61215 also contains a test sequence of UV exposure, 50 thermal cycles and 10 humidity freeze cycles. This sequence is more likely to cause delamination than damp heat alone will. The UV exposure is designed to stress the adhesion between glass and encapsulant and between the encapsulant and the cells. Once this adhesion has been weakened, the thermal cycling applies mechanical stress to adhesive bonds that may have been weakened by the UV exposure. Finally, in the humidity freeze test, humidity is forced into the module at high temperature and then when the module is rapidly cooled below freezing, any liquid water that has condensed in voids will freeze, further opening them and resulting in delaminations within the package. More delaminations are observed after this test sequence than for any of the other test legs in IEC 61215.

However, this test sequence has a number of limitations:

- The UV portion of this sequence $\left(15 \mathrm{kWh} / \mathrm{m}^{2}\right)$ is very short, representing a UV exposure of only a few months in a typical sunny terrestrial climate. This test level will not tell us how the adhesion will be impacted from years of UV exposure.

- Observation of the delaminations may not be obvious if there are no stresses applied after the humidity freeze exposure.

- Mechanical stress independent of thermal cycling is not addressed. This may be particularly important for glass/glass constructions.

To address these limitations, we propose the following changes to this test sequence in the Comparative Sequence:

- Significantly increase the UV exposure to begin the sequence, with the temperature of the UV exposure modified to fit the climate zones and mounting configuration.

- Add a dynamic mechanical loading test in accordance with IEC-62782TS [11] after the UV exposure.

- Add a damp heat test with conditions modified for climate zones after the humidity freeze test to provide moisture that can penetrate into any of the delaminations and cause the type of corrosion seen in the field.

\subsection{Test leg for encapsulant discoloration}

Analysis of field data for many PV systems by Jordan, et.al [12] has shown that long term degradation in power of crystalline silicon modules correlates with loss of short circuit current. Much of the loss of short circuit current can be attributed to discoloration of the encapsulant used in the module. Jordan noted than about $2 / 3$ of the papers on system degradation noted at least some discoloration of the encapsulant. STR has reported on the development of a UV test to evaluate whether a particular encapsulant will discolor in the field [13].

A series of UV exposure experiments are now being conducted to determine the acceleration rates and activation energies associated with UV discoloration of encapsulants [14]. The results of these experiments will be utilized to propose UV tests that should be performed on encapsulation and frontsheet materials designed for use in PV modules. These material level tests will use coupons to evaluate the ability of encapsulants and frontsheets to survive long term outdoor exposure to the sun. A UV test similar to that proposed for encapsulants in Qualification Plus [15] [16] is envisioned. In this test the materials are packaged in coupons that have similar cross sections as modules and subjected to approximately 6 months of continuous UV exposure in a test chamber at elevated temperatures to evaluate their ability to retain their optical transmission in the outdoor environment.

\section{TEST SEQUENCE}

A flow chart of the proposed Comparative Test Sequence is shown in Figure 6. Table 3 provides details of the proposed system, showing the differences based on climate zones and mounting configurations. In summary: 
Figure 6: Flow Chart of Proposed Comparative Test Plan

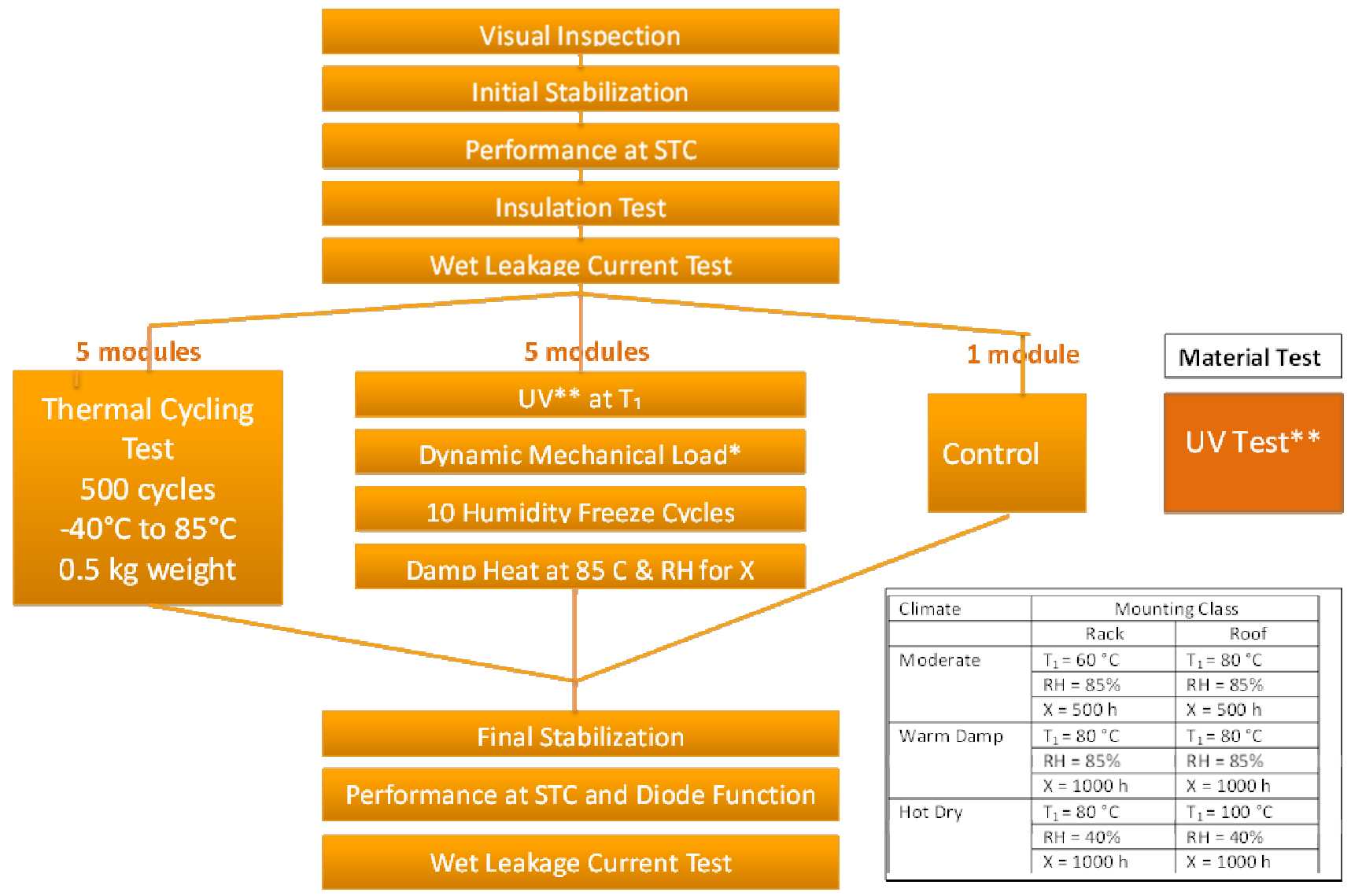

* Details specified in Draft Standard

** UV Exposure TBD

Table 3: Details of the proposed testing levels

\begin{tabular}{|c|c|c|}
\hline IEC 60721-2-1 & \multicolumn{2}{|c|}{ Mounting Class } \\
\hline & Rack Mount & Roof Mount \\
\hline $\begin{array}{l}\text { Moderate } \\
\text { (Temperate) }\end{array}$ & $\begin{array}{c}\text { Leg 1: } 500 \text { thermal cycles } \\
\text { Leg 2: Increased UV exposure at } 60^{\circ} \mathrm{C} \text { followed } \\
\text { by DML, } 10 \text { cycles of } \mathrm{HF} \text { and } 500 \text { hours of } \\
\text { Damp Heat }(85 / 85)\end{array}$ & $\begin{array}{c}\text { Leg 1: } 500 \text { thermal cycles } \\
\text { Leg 2: Increased UV exposure at } 80{ }^{\circ} \mathbf{C} \\
\text { followed by DML, } 10 \text { cycles of } \mathrm{HF} \text { and } \mathbf{5 0 0} \\
\text { hours of Damp Heat }(85 / 85)\end{array}$ \\
\hline $\begin{array}{l}\text { Warm Damp } \\
\text { Equable } \\
\text { (Tropical) }\end{array}$ & $\begin{array}{c}\text { Leg 1: } 500 \text { thermal cycles } \\
\text { Leg 2: Increased UV exposure at } 80^{\circ} \mathrm{C} \text { followed } \\
\text { by DML, } 10 \text { cycles of HF and } 1000 \text { hours of } \\
\text { Damp Heat }(85 / 85)\end{array}$ & $\begin{array}{c}\text { Leg 1: } 500 \text { thermal cycles } \\
\text { Leg 2: Increased UV exposure at } 80^{\circ} \mathrm{C} \\
\text { followed by DML, } 10 \text { cycles of } \mathrm{HF} \text { and } \mathbf{1 0 0 0} \\
\text { hours of Damp Heat }(85 / 85)\end{array}$ \\
\hline $\begin{array}{l}\text { Extremely } \\
\text { Warm Dry } \\
\text { (Desert) }\end{array}$ & $\begin{array}{c}\text { Leg 1: } 500 \text { thermal cycles } \\
\text { Leg 2: Increased UV exposure at } 80^{\circ} \mathrm{C} \text { followed } \\
\text { by DML, } 10 \text { cycles of } \mathrm{HF} \text { and } 1000 \text { hours of } \\
\text { Damp Heat }(85 / 40)\end{array}$ & $\begin{array}{c}\text { Leg 1: } 500 \text { thermal cycles } \\
\text { Leg 2: Increased UV exposure at } 100{ }^{\circ} \mathrm{C} \\
\text { followed by DML, } 10 \text { cycles of } \mathrm{HF} \text { and } 1000 \\
\text { hours of Damp Heat }(85 / 40)\end{array}$ \\
\hline
\end{tabular}

- Leg 1 consists of 500 thermal cycles for all climate zones and mounting configurations. The preliminary proposal is to use the standard IEC 61215 cycle from $-40^{\circ} \mathrm{C}$ to $+85^{\circ} \mathrm{C}$ with maximum power current flow 
when the modules are above room temperature for all climate zones and mounting configurations although consideration will be given to modifying the range based on climate and mounting.

- Leg 2 is designed to cause delaminations. It contains 3 climate/mounting specific items as described in Table 3.

1. The initial UV test is performed at 3 different temperatures.

2. The damp heat test is performed at 2 different humidity levels.

3. The damp heat test is performed for 2 different length of time

- UV material test has been proposed as a single evaluation test to determine whether a particular encapsulant or frontsheet will discolor during use.

\section{PASS FAIL CRITERIA}

IEC 61215 contains specific pass/fail criteria for the different tests. The initial proposal is to use these as a basis for establishing pass/fail for legs 1 and 2. These include:

a) the degradation of maximum output power does not exceed the prescribed limit after each test (usually 5\%) nor $8 \%$ after each test sequence (light exposures are used to remove any short-term metastabilities or transients in performance before the performance measurements);

b) no sample has exhibited any open circuit during the tests;

c) there is no visual evidence of a major defect, as defined in IEC 61215 Clause 7;

d) the insulation test requirements are met after the tests;

e) the wet leakage current test requirements are met at the beginning and the end of each

sequence;

f) specific requirements of the individual tests are met.

One additional recommendation is to add a diode check at the end of the two test sequences. Since an open circuited diode does not affect module output power, a special diode check is necessary to determine that the diode has survived the accelerated stress tests and is still capable of performing its function.

\section{NEXT STEPS}

One of the next steps in the development of the Comparative Test Standard is to begin a detailed discussion throughout the PV community about exactly what are the correct parameters that should appear in Table 3 and Figure 6 . There are still a number of issues that must be decided including:

- The number of thermal cycles to perform in Leg 1.

- What overall UV dose should be used in leg 2?

- What UV test conditions should be used in leg 2?

- Do we include thermal cycling in leg 2 and if so how many cycles do we perform?

- Exactly what material UV tests do we add?

Making decisions on these specific questions will go a long way toward finalizing the comparative testing standard.

\section{REFERENCES}

[1] IEC 61215 Ed 2 "Crystalline Silicon Terrestrial Photovoltaic (PV) Modules-Design Qualification and Type Approval." IEC Central Office: Geneva, Switzerland, 2005.

[2] IEC 61646 Ed 2 "Thin Film Terrestrial Photovoltaic (PV) Modules—Design Qualification and Type Approval." IEC Central Office: Geneva, Switzerland, 2008.

[3] Whipple, 1993.

[4] IEC 60721-2-1 Ed 2 "Classification of environmental conditions Part 2-1: Environmental conditions appearing in nature - temperature and humidity", 2013. 
[5] K. Kato, "PVRessQ!; A Research Activity on Reliability of PV Systems from a User's Viewpoint in Japan" SPIE, $10.1117 / 12 / 896135,2011$.

[6] J.H. Wohlgemuth, D.W. Cunningham, D. Amin, J. Shaner, Z. Xia, J. Miller, "Using Accelerated Tests and Field Data to Predict Module Reliability and Lifetime" 23rd EU PVSEC, p.2663-2669, 2008.

[7] W. Herrmann, N. Bogdanski, "Outdoor Weathering of PV Modules - Effects of Various Climates and Comparison with Accelerated Laboratory Testing" 37th IEEE PVSC, p 002305-002311, 2011.

[8] G. Kinsey, D. Meakin, C. Schmid, C. Ferrara, S. Stecklum, "Results of the First Round of the Photovoltaic Durability Initiative", 39th IEEE PVSC. 2013.

[9] J.H. Wohlgemuth, D.W. Cunningham, A.M. Nguyen, J. Miller, "Long Term Reliability of PV Modules", 20th EUPVSEC, 2005, p. 1942.

[10] J.H. Wohlgemuth, M. Kempe, "Equating Damp Heat Testing with Field Failures of PV Modules, 39th IEEE PVSC, 2013.

[11] IEC-62782TS - "Dynamic Mechanical Load Testing for Photovoltaic (PV) Modules", draft standard under development.

[12] D.C. Jordan, J.H. Wohlgemuth, S.R. Kurtz, "Technology and Climate Trends in PV Module Degradation" 27th EU PVSEC, p. 311803124, 2012.

[13] William H. Holley, Jr., Susan C. Agro, James P. Galica, Lynne k Thoma, Robert S. Yorgensen, Myer Ezrin, Peter Klemchuk, Gary Lavigne, Holly Thomas, "Investigation into the causes of browning in EVA encapsulate flat plate PV modules", $1^{\text {st }}$ WCPEC, 1994, p. 893.

[14] D.C. Miller, J. Bath, M. Köhl, T. Shioda, "IEC Quality Assurance TG5: UV, Temperature and Humidity", NRELPR-5200-61493, NREL PV Module Reliability Workshop, 2014.

[15] S. Kurtz, J. Wohlgemuth, M. Kempe, N. Bosco, P. Hacke, D. Jordan, D. Miller, T. Silverman, N. Phillips, T. Earnest and R. Romero, "Photovoltaic Module Qualification Plus Testing", NREL/TP-5200-60950, 2013.

[16] J. Wohlgemuth and S. Kurtz, "Photovoltaic Module Qualification Plus Testing", 40th IEEE PVSC, 2014. 